\title{
Aproximación al sistema de solución de diferencias de la Organización Mundial del Comercio. Estudio de casos
}

\section{Approach to the world trade organization's dispute settlement system (WTO). Case studies}

Carolina Lourdes Rodríguez Aguilera

Universidad Simón Bolívar, Venezuela

Autor para correspondencia: rodriguezcarol@usb.ve

Fecha de recepción: 07 de Agosto 2017 - Fecha de aceptación: 15 de Marzo de 2018

\begin{abstract}
Resumen
El objetivo de este trabajo es analizar el sistema de solución de diferencias de la Organización Mundial del Comercio, particularmente se hará énfasis en el Órgano de Apelación. Para ese fin, se examinaron algunos casos en materia de salvaguardia comercial. Asimismo, es preciso señalar que la metodología utilizada en la presente investigación se tipifica como documental descriptiva y analítica. Este enfoque permitió obtener información relevante sobre las características de los acuerdos comerciales, el funcionamiento del mecanismo jurídico para resolver las disputas comerciales entre los países miembros de la OMC, y la doctrina jurídica que sirve de referencia como fuente del derecho para otras causas. Por tanto, este trabajo se estructuró partiendo de la revisión de información especializada de la Organización Mundial del Comercio, el Acuerdo sobre Salvaguardias y bibliográficas.
\end{abstract}

Palabras Clave: solución de diferencias; organización mundial del comercio; órgano de apelación; salvaguardias

\begin{abstract}
The aim of this paper is to analyze the dispute settlement system of the World Trade Organization, particularly the emphasis on the Appellate Body. To that end, a number of cases were examined in the area of trade safeguarding. Likewise, it should be noted that the methodology used in this research is typified as descriptive and analytical documentary. This approach provided relevant information on the characteristics of trade agreements, the functioning of the legal mechanism for resolving trade disputes between WTO member countries, and the legal doctrine that serves as a reference as a source of law for other causes. Therefore, this work was structured based on the review of specialized information from the World Trade Organization, the Agreement on Safeguards and bibliographies.
\end{abstract}

Key Words: dispute settlement; world trade organization; appellate body; safeguards 


\section{Introducción}

Las reglas de la Organización Mundial del Comercio (OMC) y su sistema de resolución de disputas constituyen instituciones para tratar las controversias comerciales que garanticen cierto rango de previsión y seguridad. Igualmente, las negociaciones son un mecanismo importante que disponen los países para tratar de llegar a un acuerdo, su detenimiento o avance son cardinales para la configuración del sistema de comercio internacional. Desde la perspectiva multilateral, es oportuno destacar a grandes rasgos que el sistema multilateral del comercio actual comprende un conjunto de normas de derecho internacional público, así como, instituciones que rigen el intercambio de bienes y servicios. Las instituciones pretenden cumplir una función muy importante con el objetivo de dotar de previsibilidad y orden a las relaciones comerciales internacionales cómo estaba previsto en el GATT 47, y ahora luego de los Acuerdos de Marrakech, se extiende hacia otros sectores como los servicios y la propiedad intelectual (Pérez Gabilondo, 2004).

En ese orden de ideas, este trabajo propone desarrollar una breve aproximación al funcionamiento del Sistema de Solución de Diferencias de la Organización Mundial del Comercio; y se examinarán algunos casos resueltos por el Órgano de Apelación en materia de salvaguardia comercial. Es pertinente señalar que el Órgano de Apelación tiene su sede en Ginebra y fue fundado en 1995 de acuerdo con lo estipulado en el artículo 17 del Entendimiento relativo a las normas y procedimientos por los que se administra la solución de diferencias (ESD). Es un órgano permanente constituido por siete personas, que se encarga de las apelaciones de los informes presentados por los grupos especiales en las diferencias de los países miembros de la OMC. Asimismo, es menester indicar que los informes del Órgano de Apelación, una vez adoptados por el Órgano de Solución de Diferencias (OSD), deben ser aceptados por las partes de la diferencia.

Conviene destacar que entre los años 1996 y 2016, la OMC (2017) reporta 141 informes del Órgano de Apelación relativos a diversas causas, entre los cuales, se registran 9 casos que tienen por origen el Acuerdo de Salvaguardias multilateral. Estos casos son: 1) Argentina Medidas de salvaguardia impuestas a las importaciones de calzado (WT/DS121/AB/R, 1999) que involucró a Argentina y las Comunidades Europeas; 2) Corea - Medida de salvaguardia definitiva impuesta a las importaciones de determinados productos lácteos (WT/DS98/AB/R y Corr.1, 2000) tuvo como partes a Corea y las Comunidades Europeas; 3) Estados UnidosMedidas de salvaguardia definitivas impuestas a las importaciones de gluten de trigo procedentes de las Comunidades Europeas (WT/DS166/AB/R, 2001); 4) Estados Unidos-Medidas de salvaguardia respecto de las importaciones de carne de cordero fresca, refrigerada o congelada procedentes de Nueva Zelandia y Australia, (WT/DS177/AB/R, WT/DS178/AB/R, 2001); 5) Estados Unidos- Medida de salvaguardia de transición aplicada a los hilados peinados de algodón procedentes del Pakistán, (WT/DS192/AB/R, 2001): 6) Estados Unidos-Medida de salvaguardia definitiva contra las importaciones de tubos al carbono soldados de sección circular procedentes de Corea,(WT/DS202/AB/R, 2002); 7) Chile-Sistema de bandas de precios y medidas de salvaguardia aplicados a determinados productos agrícolas (WT/DS207/AB/R, 2002); 8) Estados Unidos-Medidas de salvaguardia definitivas sobre las importaciones de determinados productos de acero, Brasil, China, Comunidades Europeas, Corea, Estados Unidos, Japón, Noruega, Nueva Zelandia, Suiza (WT/DS259/AB/R, 2003); y, 9) Chile-Sistema de bandas 
de precios y medidas de salvaguardia aplicados a determinados productos agrícolas: Recurso de la Argentina al párrafo 5 del artículo 21 del ESD, Chile-Argentina (WT/DS207/AB/RW, 2007).

Ahora bien, con la finalidad de ilustrar el funcionamiento del sistema de solución de diferencias en el área de salvaguardias comerciales, se seleccionaron como representación de diferencias que involucran a países vinculados simultáneamente a organizaciones regionales y multilaterales de comercio, los siguientes casos:

a) Informe del Órgano de Apelación, Argentina- Medidas de Salvaguardia impuestas a las importaciones de Calzado, identificado como WT/DS121/AB/R, de 14 de diciembre de 1999, AB-1999-7.

B) Informe del Órgano de Apelación, Estados Unidos-Medida de Salvaguardia definitiva contra las importaciones de tubos al carbono soldados de sección circular procedentes de Corea, identificado como WT/DS202/AB/R, de 15 de febrero de 2002, AB-2001-9.

c) Informe del Órgano de Apelación, Estados Unidos-Medidas de Salvaguardia definitivas sobre las importaciones de determinados productos de acero, identificado como WT/DS259/AB/R, de 10 de noviembre de 2003, AB-2003-3.

Es preciso subrayar la múltiple pertenencia de los países a distintas organizaciones de comercio internacional, sobre el particular, Rojas Aravena y Altman (2006:4) sostienen lo siguiente:

La complementariedad entre los distintos niveles de integración es compleja; las agendas subregionales, regionales, hemisféricas y globales abordan y ponen énfasis diferentes en diversos aspectos. En ellos las arenas y los escenarios en que se desarrollan impactan a los más diversos actores. De allí que esencial el producir coordinación. Sin ella cada uno de los procesos será visto desde una perspectiva sectorial sin ningún tipo de vínculos entre ellos, y en definitiva, se reafirma la fragmentación y las reducidas capacidades de concertación transnivel desde lo nacional a lo global.

En ese escenario, los sistemas de solución de controversias y los ordenamientos jurídicos desempeñan una función muy importante, para resolver las diferencias que se presentan en la aplicación de los acuerdos, así como para reforzar el cumplimiento de las obligaciones adquiridas. Además, su relevancia merece ser destacada, entre otras razones porque contribuye a la seguridad jurídica y eso incidirá en las relaciones económicas internacionales (Iglesias, 2004).

Los teóricos de los regímenes internacionales como Hasencleaver, Mayer y Volker Rittberger (1999) consideran que las leyes son creadas y obedecidas en función de intereses propios o de conveniencias, coincidiendo con Hurrell (1992). Por su parte, Krasner (1976) sostiene que los regímenes internacionales son principios, normas, reglas y procedimientos de toma de decisiones, explícita o implícita, alrededor de los cuales convergen las expectativas de los actores en áreas específicas de las relaciones internacionales. Esto nos lleva a un punto crucial de los regímenes, cómo es la obediencia de los Estados. Son variadas las motivaciones, poder y coerción, interés propio y beneficios recíprocos, costumbre institucionalizada o inercia, la existencia de un sentido de comunidad, la legitimidad o persuasión moral de un sentido compartido de justicia (Hurrell, 1992: 650). En este sentido, se explicará previamente de manera 
sucinta el mecanismo de la salvaguardia multilateral y el funcionamiento del sistema de solución de diferencias en la OMC.

\section{La salvaguardia multilateral}

En el espacio multilateral, la salvaguardia consiste en un mecanismo mediante el cual un miembro de la Organización Mundial del Comercio, puede restringir de forma temporal las importaciones de un producto, si las importaciones de ese producto han aumentado en tal cantidad que causan o amenazan causar daño a una rama de producción nacional (Acuerdo sobre Salvaguardias de la OMC, artículo 2). El efecto de la medida de salvaguardia, por una parte protege o beneficia al productor del país que se encuentra afectado por las importaciones de otros países, pero por otra parte, afecta al país que hasta ese momento se encontraba exportando de manera eficiente su producción. Debe acotarse que las restricciones a las importaciones a través de medidas de salvaguardias, pueden darse bajo las modalidades de gravámenes, contingentes $\mathrm{u}$ otro tipo de controles a las importaciones. También es una paradoja frente a la libertad de comercio que propugna la OMC.

Sobre el particular, y siguiendo con lo que ya se ha adelantado, es pertinente destacar que las medidas de salvaguardias han sido definidas por el Órgano de Apelación como medidas extraordinarias en los siguientes términos:

Las medidas de salvaguardias se tratan de medidas correctivas que se imponen en forma de restricciones a la importación sin que se alegue una práctica comercial desleal. A este respecto, las medidas de salvaguardia difieren, por ejemplo, de los derechos antidumping y de los derechos compensatorios para contrarrestar las subvenciones, al tratarse en ambos casos de medidas adoptadas en respuesta a prácticas comerciales desleales. Por lo tanto, en caso de que se cumplan las condiciones necesarias para ello, las medidas de salvaguardia pueden imponerse con respecto al "comercio leal" de los demás Miembros de la OMC y, al limitar sus importaciones, impedirán que esos Miembros obtengan las ventajas plenas de las concesiones comerciales en el marco del Acuerdo sobre la OMC. (Órgano de Apelación, WT/DS202/AB/R, 2002, párrafo 80).

En ese orden de ideas, el carácter extraordinario debe tenerse en cuenta cuando se interpretan los requisitos previos para la adopción de tales medidas:

Para lograr este objeto y fin declarados del Acuerdo sobre Salvaguardias, debe tenerse en todo momento en cuenta que las medidas de salvaguardia dan lugar a la suspensión temporal de las concesiones o a la no aplicación de obligaciones que son fundamentales para el Acuerdo sobre la OMC, como las establecidas en los artículos II y XI del GATT de 1994. Por tanto, las medidas de salvaguardia sólo se pueden aplicar cuando se han demostrado reunidos los requisitos de las disposiciones del Acuerdo sobre Salvaguardias y del artículo XIX del GATT de 1994. (Órgano de Apelación, WT/DS202/AB/R, 2002, Párrafos 81, 93)

De lo expuesto anteriormente, se desprenden las características de las medidas de salvaguardia, a saber: a) carácter extraordinario; y b) su aplicación temporal. Son elocuentes las palabras emitidas por el Órgano de Apelación (WT/DS202/AB/R, 2002, Párrafo 83) cuando observa que: 
Hay por consiguiente una tensión natural entre la necesidad de definir el ámbito apropiado y legítimo del derecho de aplicar medidas de salvaguardia, de una parte, y la de garantizar que las medidas de salvaguardia no se apliquen frente al "comercio leal" más de lo necesario para ofrecer un recurso paliativo de carácter extraordinario y temporal, de otra. El Miembro de la OMC que se proponga aplicar una medida de salvaguardia aducirá, con razón, que es preciso respetar el derecho a aplicar medidas de esa naturaleza para mantener el impulso y la motivación internas que requiere la liberalización del comercio en curso. A su vez, el Miembro de la OMC cuyo comercio se vea afectado por una medida de salvaguardia aducirá, justificadamente, que es preciso limitar la aplicación de ese género de medidas para preservar la integridad multilateral de las concesiones comerciales vigentes. El equilibrio establecido por los Miembros de la OMC para resolver esa tensión natural en relación con las medidas de salvaguardia se materializa en las disposiciones del Acuerdo sobre Salvaguardias.

Por consiguiente, es preciso destacar que la salvaguardia de la OMC requiere:

a) que las importaciones de un producto determinado en su territorio han aumentado en tal cantidad y se realizan en condiciones tales que causan o amenazan causar un daño grave a la rama de producción nacional;

b) demostrar la relación de causalidad entre el aumento de las importaciones y el daño grave o la amenaza de daño grave.

\section{Breve explicación sobre el funcionamiento del sistema de solución de diferencias de la OMC}

Es oportuno recordar que el mecanismo de solución de diferencias de la OMC fue creado en 1995, vale destacar que el artículo 3.2 del Entendimiento sobre Solución de Diferencias (ESD) resume muy bien la idea de lo que comprende, al disponer que el sistema de solución de diferencias de la OMC es un elemento esencial para aportar seguridad y previsibilidad al sistema multilateral de comercio. Asimismo, Lacarte y Granados (2004: 63) señalan que:

El objetivo del mecanismo de solución de diferencias es hallar una solución positiva a las diferencias (Artículo 3.7. ESD), además de resaltar que el primer objetivo del mecanismo de solución de diferencias será conseguir la supresión de las medidas de que se trate, si se constata que estas son incompatibles con las disposiciones de cualquiera de los acuerdos abarcados.

El sistema de solución de diferencias, es un procedimiento que han convenido los países miembros, en el supuesto que consideren que otro país miembro ha infringido una norma comercial multilateral, caso en el cual, se estarían incumpliendo obligaciones contraídas. El procedimiento de solución de diferencias contenido en el ESD de la OMC, básicamente puede resumirse de la siguiente manera: a) las partes en una diferencia deben celebrar consultas con el fin de buscar la solución de la misma; b) Si no se logra una solución, las partes podrían someter la diferencia a un Grupo Especial; c) Una vez que el Grupo especial emite su pronunciamiento, dicha decisión podrá ser recurrida ante el Órgano de Apelación, con base en cuestiones de derecho; y, d) Luego sigue una etapa de aplicación de las resoluciones o de retorsión. 
La solución de diferencias es competencia del órgano de solución de diferencias, integrada por todos los miembros de la OMC. Este órgano está facultado para designar los grupos especiales de expertos que examinarán la diferencia. Así también, cabe agregar que el OSD debe observar la aplicación de las resoluciones y recomendaciones, y en el caso que corresponda, tiene potestad para autorizar medidas de retorsión cuando un país no acate una resolución, como suspensión de concesiones u otros derechos, con carácter temporal y excepcional (Hummer \&Prager, 1998:25).

El tema de la solución de diferencias comerciales es de gran importancia, y la dinámica de las relaciones comerciales los reclama como necesario, en ese orden, Lacarte y Granados (2004: 397) coinciden en esgrimir que:

El éxito de las relaciones comerciales internacionales depende en gran medida de la credibilidad que tengan los múltiples instrumentos jurídicos internacionales que hoy las gobiernan, no sólo en los términos clásicos de permitir el acceso a los mercados de bienes, servicios e inversión, sino también, porque dichos instrumentos brindan seguridades para el productor, el comerciante y el inversionista.

Se espera que el sistema de solución de diferencias ayude a profundizar y velar por el cumplimiento de determinados objetivos, no obstante, también debe tomarse en cuenta, que los países pueden estar insertos en situaciones internas, por ejemplo, proteger determinados sectores productivos de la producción nacional, que podrían llevarlos a que por acción u omisión infrinjan algunos compromisos. Además, puede argumentarse que el sistema jurídico internacional puede contribuir a estabilizar y reforzar el Estado de derecho en los países, y a la vez, la competencia normativa que se adjudican algunos órganos de las organizaciones internacionales enriquece el ordenamiento internacional con normas derivadas que servirán de guía para la solución pacífica de las controversias (Czar de Zalduendo, 2007).

La interdependencia asimétrica (Keohane y Nye, 1987) que caracteriza a los países demanda mayores esfuerzos y necesidad de coordinación. Desarrollar mecanismos de entendimiento y de interpretación de los acuerdos, profundizar en el conocimiento e implementación de los diversos sistemas de solución de controversias puede resultar un aspecto relevante a la hora del afianzamiento de las relaciones comerciales y para atraer inversiones tanto nacionales como extranjeras para impulsar el desarrollo económico de los países. En ese sentido, parece interesante indagar sobre la perspectiva de la OMC, en materia de salvaguardias, a partir del examen de casos, y analizar lo que haya concluido el Órgano de Apelación de la OMC.

\section{Análisis de casos en materia de salvaguardia comercial en la OMC}

Una primera observación que se debe hacer, es que en los casos que se revisaron, se pudieron hallar algunos pronunciamientos que pueden servir para ir deslindando el tema, sobre los supuestos para la aplicación de una medida de salvaguardia de la OMC; ámbito de aplicación; y sobre el alcance de una investigación en materia de salvaguardia.

Otro punto a destacar de los casos de estudio, es que el Órgano de Apelación no analizó el tema sobre si la pertenencia o no a una zona preferencial de comercio, una unión aduanera, 
permite o no excluir o dar un trato preferente a las importaciones originarias de esa zona, frente a la aplicación de una medida de salvaguardia multilateral, debido a que no fueron planteados por las partes específicamente en la diferencia. Cabe distinguir que el Sistema General "Agreement on Tariffs and Trade" (GATT) o Acuerdo General sobre Aranceles Aduaneros y Comercio y la Organización Mundial del Comercio GATT/OMC, autoriza la creación de áreas de libre comercio mediante el artículo XXIV del GATT (bienes), el GATS (servicios) y la cláusula de habilitación (enabling clause) de preferencias para los países en desarrollo.

Sin embargo, se observó que hay elementos que permiten delimitar el criterio entre la relación que se produce cuando se realiza una investigación y la aplicación de las medidas de salvaguardia. Otra advertencia que debe hacerse, es que si bien son diversos los argumentos que las partes en cada caso someten a apelación, a los efectos de la presente propuesta de estudio, sólo se hará énfasis puntualmente a algunos aspectos que se consideran de utilidad para nuestra investigación, de forma tal de no extendernos en apreciaciones que desborden lo que se pretende debatir en este trabajo.

Específicamente nos referiremos a los siguientes casos (OMC, 1999; 2001; 2003):

a) Informe del Órgano de Apelación, Argentina- Medidas de Salvaguardia impuestas a las importaciones de Calzado, identificado como WT/DS121/AB/R, de 14 de diciembre de 1999, AB-1999-7;

El primer caso a explorar involucró a Argentina y las Comunidades Europeas, quienes apelaron a cuestiones de derecho del informe del Grupo Especial que examinó el asunto Argentina-Medidas de salvaguardia impuestas a las importaciones de calzado. Las normas objeto de análisis fueron los artículos 2 y 4 del Acuerdo sobre Salvaguardias. Cabe destacar que el artículo 2 del Acuerdo sobre Salvaguardias, establece lo siguiente:

\section{Condiciones}

1. Un Miembro sólo podrá aplicar una medida de salvaguardia a un producto si dicho Miembro ha determinado, con arreglo a las disposiciones enunciadas infra, que las importaciones de ese producto en su territorio han aumentado en tal cantidad, en términos absolutos o en relación con la producción nacional, y se realizan en condiciones tales que causan o amenazan causar un daño grave a la rama de producción nacional que produce productos similares o directamente competidores.

2. Las medidas de salvaguardia se aplicarán al producto importado independientemente de la fuente de donde proceda.

Mientras que, el artículo 4 del Acuerdo sobre Salvaguardias dispone la determinación de la existencia de daño grave o de amenaza de daño grave en los siguientes términos:

1. A los efectos del presente Acuerdo:

a) se entenderá por "daño grave" un menoscabo general significativo de la situación de una rama de producción nacional; 
b) se entenderá por "amenaza de daño grave" la clara inminencia de un daño grave, de conformidad con las disposiciones del párrafo 2. La determinación de la existencia de una amenaza de daño grave se basará en hechos y no simplemente en alegaciones, conjeturas o posibilidades remotas; y

c) para determinar la existencia de daño o de amenaza de daño, se entenderá por "rama de producción nacional" el conjunto de los productores de los productos similares o directamente competidores que operen dentro del territorio de un Miembro o aquellos cuya producción conjunta de productos similares o directamente competidores constituya una proporción importante de la producción nacional total de esos productos.

2.

a) En la investigación para determinar si el aumento de las importaciones ha causado o amenaza causar un daño grave a una rama de producción nacional a tenor del presente Acuerdo, las autoridades competentes evaluarán todos los factores pertinentes de carácter objetivo y cuantificable que tengan relación con la situación de esa rama de producción, en particular el ritmo y la cuantía del aumento de las importaciones del producto de que se trate en términos absolutos y relativos, la parte del mercado interno absorbida por las importaciones en aumento, los cambios en el nivel de ventas, la producción, la productividad, la utilización de la capacidad, las ganancias y pérdidas y el empleo.

b) No se efectuará la determinación a que se refiere el apartado a) del presente párrafo a menos que la investigación demuestre, sobre la base de pruebas objetivas, la existencia de una relación de causalidad entre el aumento de las importaciones del producto de que se trate y el daño grave o la amenaza de daño grave. Cuando haya otros factores, distintos del aumento de las importaciones, que al mismo tiempo causen daño a la rama de producción nacional, este daño no se atribuirá al aumento de las importaciones.

c) Las autoridades competentes publicarán con prontitud, de conformidad con las disposiciones del artículo 3, un análisis detallado del caso objeto de investigación, acompañado de una demostración de la pertinencia de los factores examinados."

En este caso hay dos temas de consideración, uno relacionado con la aplicación de medidas de salvaguardia por un miembro de una unión aduanera, donde la Argentina alega que el Grupo Especial habría errado en su razonamiento legal y en su interpretación del Acuerdo sobre Salvaguardias, en lo que respecta al derecho de la Argentina a excluir a sus interlocutores del MERCOSUR de la aplicación de las medidas de salvaguardia; otro argumento sostenido por la Argentina, es que el Grupo Especial incurrió en error de derecho al imponer un "requisito de paralelismo", que no se encuentra en el Acuerdo sobre Salvaguardias, entre la determinación de la existencia de daño y la aplicación de la medida de salvaguardia. (OMC, 1999: Párrafo 14).

Ahora bien, según se recoge en el informe del Órgano de Apelación, la Argentina aplicó la medida de salvaguardia en cuestión, después de una investigación efectuada por las autoridades argentinas sobre los efectos en la rama de producción argentina de las importaciones procedentes de todas las fuentes (OMC, 1999: Párrafo 107). 
Es preciso advertir, que el Órgano de Apelación no entró a analizar el artículo XXIV del GATT de 1994, porque no lo consideró pertinente en este caso, sin embargo, se refirió a un punto que es muy interesante de examinar, relativo al alcance de una investigación sobre salvaguardia, esto es importante destacarlo, porque se establece una precisión sobre el alcance de una investigación en materia de salvaguardia y el alcance de la aplicación de una medida de salvaguardia, al respecto el Órgano de Apelación de la OMC sostuvo que:

Aunque el párrafo 1 del artículo 2 y el párrafo 1 c) del artículo 4 establecen las condiciones para la aplicación de una medida de salvaguardia y los requisitos relativos al alcance de una investigación en materia de salvaguardia, estas disposiciones no resuelven la cuestión del alcance de la aplicación de una medida de salvaguardia. En ese contexto, el párrafo 2 del artículo 2 del Acuerdo sobre Salvaguardias establece: Las medidas de salvaguardia se aplicarán al producto importado independientemente de la fuente de donde proceda.

El Órgano de Apelación sustenta que:

Como hemos observado, en el caso presente la Argentina aplicó las medidas de salvaguardia en cuestión después de realizar una investigación sobre los productos importados en el territorio argentino y sobre los efectos de esas importaciones en la rama de producción nacional de la Argentina. Al aplicar medidas de salvaguardia basadas en la investigación realizada en este caso, la Argentina también debió, de conformidad con el párrafo 2 del artículo 2, aplicar esas medidas a las importaciones procedentes de todas las fuentes, con inclusión de las de otros Estados miembros del MERCOSUR.( OMC, 1999: Párrafo 112).

Esto lo sostuvo el Órgano de Apelación al constatar que la investigación realizada por la Argentina evaluó si las importaciones procedentes de todas las fuentes causaban o amenazaban causar un daño grave, por lo que entonces, sólo podía dar lugar a la aplicación de medidas de salvaguardia a las importaciones procedentes de todas las fuentes. Por lo que, el Órgano de Apelación concluyó que la investigación realizada por la Argentina en el caso presente, no puede servir como base para excluir a las importaciones procedentes de otros Estados miembros del MERCOSUR de la aplicación de las medidas de salvaguardia. (OMC, 1999: Párrafo 113).

Este razonamiento encuentra soporte en el análisis de todos los factores intervinientes en una investigación de salvaguardia, y en la relación de causalidad entre el aumento de las importaciones y el daño grave o amenaza de daño grave. Lo que supondría pensar que si durante una investigación se examinan el comportamiento de las importaciones de todas las fuentes, las mismas deberán ser tomadas en cuenta para determinar de dónde proviene el daño, sin excepciones. Pareciera entonces, que la medida de salvaguardia esté destinada a corregir un daño en la producción nacional y su aplicación se enfoca a las importaciones de ese producto que están produciendo daño, sin distinguir el origen.

Más precisamente, el Órgano de Apelación señaló que:

Concluimos que la Argentina no puede justificar, teniendo en cuenta los hechos del caso presente, la aplicación de sus medidas de salvaguardia sólo a las fuentes de suministro de terceros países que no son miembros del MERCOSUR basándose en una investigación que constató la existencia o amenaza de daño grave causado por importaciones procedentes de 
todas las fuentes, con inclusión de las importaciones procedentes de otros Estados miembros del MERCOSUR. Sin embargo, como hemos expresado, no estamos de acuerdo en que el Grupo Especial haya tenido ante sí, habida cuenta de los hechos del caso, una medida de salvaguardia aplicada por una unión aduanera en nombre de un Estado miembro. (Párrafo 114).

Puede observarse que el cuestionamiento que hizo el Órgano de Apelación de la actuación de Argentina de excluir de la aplicación de la medida de salvaguardia a las importaciones de MERCOSUR, se fundamenta en el hecho de que Argentina durante la fase de investigación incluyó a las importaciones de todas las fuentes, y realizó su análisis sobre todas las importaciones incluyendo las de MERCOSUR, en ese orden, luego Argentina no podría excluir al momento de aplicar medidas de salvaguardia a las importaciones que tomó en cuenta durante la investigación, esto es, debe comprender todas las importaciones, esto incluiría las procedentes de MERCOSUR .

Como se mencionó al inicio, en este caso el Órgano de Apelación no entró a analizar el tema sobre si la pertenencia o no a una zona preferencial de comercio, una unión aduanera, permite o no excluir o dar un trato preferente a las importaciones originarias de esa zona, frente a la aplicación de una medida de salvaguardia multilateral. Sin embargo, este caso sirve de referencia porque comenzó a delimitarse el criterio entre la relación que se produce cuando se realiza una investigación y la aplicación de las medidas de salvaguardia.

B) Informe del Órgano de Apelación, Estados Unidos - Medida de Salvaguardia definitiva contra las importaciones de tubos al carbono soldados de sección circular procedentes de Corea, identificado como WT/DS202/AB/R, de 15 de febrero de 2002, AB-2001-9.

Los Estados Unidos y Corea apelaron contra determinadas cuestiones de derecho tratadas e interpretaciones jurídicas realizadas por el Grupo Especial, en el informe Estados Unidos Medida de salvaguardia definitiva contra las importaciones de tubos al carbono soldados de sección circular procedentes de Corea WT/DS202/AB/R, 29 de octubre de 2001, Párrafo 1 (OMC, 2001).

Este proceso también tuvo como objeto de análisis los artículos 2 y 4 del Acuerdo sobre Salvaguardias. Particularmente, el caso se refiere a la imposición por los Estados Unidos de una medida de salvaguardia definitiva contra las importaciones de tubos al carbono soldados de sección circular. Ahora bien, el detalle en este caso en cuanto a la aplicación de la medida, es que sería aplicable a las importaciones procedentes de todos los países, incluidos los Miembros de la Organización Mundial del Comercio (OMC), pero están excluidas de ella las importaciones procedentes del Canadá y de México (OMC, 2001: Párrafo 6).

En su argumentación los Estados Unidos sostuvieron que el Tratado de Libre Comercio de las Américas, (TLCAN, por sus siglas en español o NAFTA en inglés), prevé que las importaciones procedentes de partes en el Tratado queden excluidas de las medidas de salvaguardia en determinadas circunstancias. Es pertinente recordar que el artículo 802.1 medidas globales del TLCAN dispone que:

Las partes conservan sus derechos y obligaciones conforme al artículo XIX del GATT o a 
cualquier otro acuerdo de salvaguardias suscrito al amparo del mismo, excepto los referentes a compensación o represalia y exclusión de una medida en cuanto sean incompatibles con las disposiciones de este artículo. Cualquier Parte que aplique una medida de emergencia conforme a aquellas disposiciones excluirá de la medida las importaciones de bienes de cada una de las otras Partes, a menos que:

a) las importaciones de una Parte, consideradas individualmente, representen una participación sustancial en las importaciones totales; $y$,

b) las importaciones de una Parte consideradas individualmente o, en circunstancias excepcionales, las importaciones de varias Partes consideradas en conjunto, contribuyan de manera importante al daño serio o amenaza del mismo causado por dichas importaciones.( OMC, 2001: Párrafo 50).

Esta prescripción fue una de las medidas destinadas a eliminar los derechos de aduana y las demás reglamentaciones comerciales restrictivas con respecto a lo esencial de los intercambios comerciales que era necesario eliminar para establecer la zona de libre comercio. Ahora bien, por otra parte, es interesante observar como las Comunidades Europeas señalaron que el argumento de que la exclusión de las importaciones procedentes de países del TLCAN de la medida en cuestión estaba autorizada como parte de la eliminación de las restricciones necesarias para establecer una zona de libre comercio está en contradicción con los hechos (OMC, 2001: Párrafo 66). En opinión de las Comunidades Europeas, los Estados Unidos conservan facultades discrecionales para aplicar a las importaciones procedentes de países del TLCAN medidas de salvaguardia.

Ante el argumento de las Comunidades Europeas sobre las facultades discrecionales para aplicar dichas medidas, pudiera también interpretarse en sentido afirmativo o negativo, esto es, aplicar o no aplicar dichas medidas. Por lo que no parece relevante ese argumento. Por otra parte, en cuanto al ámbito de aplicación de la medida de salvaguardia, es decir, el análisis de las importaciones incluidas en la investigación, y las importaciones comprendidas en la aplicación de las medidas, este punto se trató también en el caso expuesto precedentemente, ArgentinaMedidas de Salvaguardia impuestas a las importaciones de Calzado, identificado como WT/DS121/AB/R.

Al respecto, el Órgano de Apelación con base en los precedentes en el asunto Estados Unidos - Gluten de trigo, sostuvo que:

La diferencia entre las importaciones incluidas en la investigación y las importaciones comprendidas en el ámbito de aplicación de la medida sólo se puede justificar si las autoridades competentes establecen explícitamente que las importaciones procedentes de fuentes comprendidas en el ámbito de aplicación de la medida [cumplen] las condiciones para la aplicación de la medida de salvaguardia, conforme prescribe el párrafo 1 del artículo 2 y confirma el párrafo 2 del artículo 4 del Acuerdo sobre Salvaguardias. Y, como explicamos también en el asunto Estados Unidos - Cordero, en el contexto de una reclamación formulada al amparo del párrafo 2 a) del artículo 4 del Acuerdo sobre Salvaguardias, establecer explicitamente supone que las autoridades competentes tienen que facilitar una explicación razonada y adecuada del modo en que los factores corroboran su determinación. (OMC, 2001: Párrafo 181). 
Al revisar esta exposición del Órgano de Apelación, se observa que hay una argumentación más precisa respecto al primer caso expuesto, esto es, al señalar que la diferencia entre las importaciones incluidas en la investigación y las importaciones comprendidas en el ámbito de aplicación de la medida, sólo se puede justificar si las autoridades competentes establecen explícitamente que las importaciones procedentes de fuentes comprendidas en el ámbito de aplicación de la medida cumplen las condiciones para la aplicación de la medida de salvaguardia. Pareciera estar dando cabida a que haya una diferencia entre las importaciones incluidas en la investigación de las importaciones comprendidas en la aplicación de las medidas, aunque esa diferencia estaría sujeta a una explicación razonada.

En este caso, se destaca que la investigación realizada por la Comisión de Comercio Internacional de los Estados Unidos (USITC) órgano integrado por seis miembros encargado de realizar ese tipo de investigaciones en el ordenamiento jurídico estadounidense, tomó en consideración, las importaciones procedentes de todas las fuentes, incluidas las importaciones procedentes del Canadá y México. Sin embargo, las exportaciones del Canadá y México fueron excluidas de la medida de salvaguardia. Por lo que, hay una diferencia entre las importaciones incluidas en la investigación efectuada por la USITC y las importaciones comprendidas en el ámbito de aplicación de la medida. (OMC, 2001: Párrafo 186).

Sobre ese particular, el Órgano de Apelación indicó que:

Constatamos que los Estados Unidos han infringido los artículos 2 y 4 del Acuerdo sobre Salvaguardias al incluir al Canadá y México en el análisis de si el aumento de las importaciones causó o amenazó causar daño grave, pero excluirlos de la aplicación de la medida de salvaguardia, sin proporcionar una explicación razonada y adecuada que estableciera explícitamente que las importaciones procedentes de países no miembros del TLCAN cumplían, por sí solas, las condiciones para la aplicación de la medida de salvaguardia. (OMC, 2001: Párrafo 197).

El Órgano de Apelación prosiguió aclarando que:

Al hacerlo no prejuzgamos si el párrafo 2 del artículo 2 del Acuerdo sobre Salvaguardias permite a un Miembro excluir del ámbito de aplicación de una medida de salvaguardia las importaciones procedentes de Estados miembros de una zona de libre comercio. No es necesario que nos pronunciemos, y no nos pronunciamos, sobre la cuestión de si el artículo XXIV del GATT de 1994 permite excluir de una medida las importaciones procedentes de un miembro de una zona de libre comercio apartándose de lo dispuesto en el párrafo 2 del artículo 2 del Acuerdo sobre Salvaguardias. La cuestión de si el artículo XXIV del GATT de 1994 sirve como excepción al párrafo 2 del artículo 2 del Acuerdo sobre Salvaguardias sólo resulta pertinente en dos posibles circunstancias. Una se da cuando en la investigación realizada por las autoridades competentes de un Miembro de la OMC las importaciones que están excluidas de la medida de salvaguardia no son tomadas en consideración en la determinación del daño grave. La otra se da cuando, en esa investigación, las importaciones que están excluidas de la aplicación de la medida de salvaguardia son tomadas en consideración en la determinación del daño grave y las autoridades competentes también han establecido_explícitamente, mediante una explicación razonada y adecuada, que las importaciones procedentes de fuentes ajenas a la zona de libre comercio satisfacian, por sí solas, las condiciones para la aplicación de una medida de 
salvaguardia, conforme a lo establecido en el párrafo 1 del artículo 2 y desarrollado en el párrafo 2 del artículo 4. (OMC, 2001: Párrafo 198).

Los argumentos expuestos en el párrafo anterior tienen un agregado fundamental en la sustentación que se viene realizando, dado que permitiría una excepción al párrafo 2 del artículo 2 del Acuerdo de Salvaguardia, bajo el artículo XXIV del GATT de 1994. De esta forma, se contempla la posibilidad de excluir de la aplicación de las medidas de salvaguardia a ciertas importaciones, en dos supuestos, a) cuando las importaciones que están excluidas de la aplicación de la medida de salvaguardia no fueron tomadas en consideración en la determinación del daño grave, o b) cuando, las importaciones excluidas de la aplicación de la medida de salvaguardia fueron examinadas en la determinación del daño grave, pero las autoridades competentes han establecido explícitamente, con una explicación razonada y adecuada, que las importaciones procedentes de fuentes ajenas a la zona de libre comercio satisfacían, por sí solas, las condiciones para la aplicación de una medida de salvaguardia.

Sin embargo, en este caso el Órgano de Apelación consideró que no habría justificación para la exclusión de las importaciones procedentes de Canadá y México del ámbito de aplicación de la medida, porque no fue sustentada de manera razona dicha exclusión. En ese sentido, el Órgano de Apelación sostuvo que no era necesario analizar la cuestión de si los Estados Unidos pueden invocar como defensa el artículo XXIV. Y terminó señalando que la medida referente a los tubos, es incompatible con las obligaciones que corresponden a los Estados Unidos en virtud del Acuerdo sobre Salvaguardia (OMC, 2001: Párrafo 264).

c) Informe Del Órgano de Apelación, Estados Unidos - Medidas de Salvaguardia definitivas sobre las importaciones de determinados productos de acero, identificado como WT/DS259/AB/R, de 10 de noviembre de 2003, AB-2003-3.

Se trata de unas medidas de salvaguardia definitivas sobre las importaciones de determinados productos de acero. Los Estados Unidos excluyeron las importaciones procedentes del Canadá y de México, así como las procedentes de Israel y de Jordania, del ámbito de aplicación de las medidas de salvaguardia. Cómo se verá en este caso, el Órgano de Apelación desarrolla argumentos de derecho similares a los expuestos en el caso de EEUU, tubos-Corea, expuesto anteriormente. Asimismo, las normas objeto de análisis son los artículos 2 y 4 del Acuerdo sobre Salvaguardias.

Sobre la aplicación de una medida de salvaguardia, el Órgano de Apelación señaló que: Cuando, a los fines de aplicar una medida de salvaguardia, un Miembro ha llevado a cabo una investigación, considerando que las importaciones procedentes de todas las fuentes (esto es, con inclusión de todo miembro de una zona de libre comercio), ese Miembro no puede posteriormente, sin realizar un nuevo análisis, excluir las importaciones procedentes de miembros de la zona de libre comercio, de la aplicación de la medida de salvaguardia resultante. Como hemos expresado en Estados Unidos - Tubos, si un Miembro obrara de este modo, se produciría una "diferencia" entre las importaciones incluidas en la investigación, por una parte, y por la otra las importaciones comprendidas en el ámbito de aplicación de la medida de salvaguardia. (Informe del Órgano de Apelación, Estados Unidos - Tubos, párrafo 181). Al aclarar las obligaciones de los Miembros de la OMC en virtud de los requisitos "paralelos" de 
los párrafos primero y segundo del artículo 2 del Acuerdo sobre Salvaguardias, en Estados Unidos - Tubos explicamos que tal "diferencia" podía justificarse en virtud del Acuerdo sobre Salvaguardias sólo si el Miembro establece: "explícitamente" que las importaciones procedentes de fuentes comprendidas en el ámbito de aplicación de la medida "cumplen las condiciones para la aplicación de la medida de salvaguardia, conforme prescribe el párrafo 1 del artículo 2 y confirma el párrafo 2 del artículo 4 del Acuerdo sobre Salvaguardias" (OMC, 2003: Párrafo 441).

El Órgano de Apelación añadió que para ser explícita una afirmación tiene que expresar de manera precisa todo lo que quiere decir, no debe dejar nada meramente implícito o insinuado, tiene que ser clara e inequívoca. (OMC, 2003: Párrafo 442). Estados Unidos, reconoció que, en su investigación, la USITC consideró las importaciones procedentes de todas las fuentes, con inclusión de las importaciones originarias del Canadá, Israel, Jordania y México. No obstante, las importaciones procedentes del Canadá, Israel, Jordania y México fueron excluidas de la aplicación de la medida de salvaguardia objeto del litigio. Por consiguiente, hay una diferencia entre las importaciones que se tuvieron en cuenta en la investigación realizada por la USITC y las importaciones comprendidas en el ámbito de aplicación de las medidas impuestas. (OMC, 2003: Párrafo 443). Tomando en cuenta lo explicado por el Órgano de Apelación, la USITC debió haber ofrecido una explicación razonada y adecuada del modo en que los hechos respaldaban su determinación de que las importaciones procedentes de fuentes distintas del Canadá, Israel, Jordania y México satisfacían por sí solas y consideradas aisladamente las condiciones para la aplicación de una medida de salvaguardia.

Se argumenta que la autoridad investigadora en Estados Unidos, en lugar de haber realizado dos análisis separados -excluyendo al Canadá y México o bien a Israel y Jordania-, la USITC, debería haber facilitado una única determinación conjunta apoyada explícitamente por una explicación razonada y adecuada sobre si las importaciones procedentes de fuentes distintas del Canadá, Israel, Jordania y México, por sí solas, satisfacían las condiciones para la aplicación de una medida de salvaguardia. (OMC, 2003: Párrafo 468). En ese contexto, el Órgano de Apelación consideró que las medidas de salvaguardia analizadas eran incompatibles con el Acuerdo sobre Salvaguardias y el GATT de 1994, y recomendó que el Órgano de Solución de Diferencias pidiera a los Estados Unidos que colocara sus medidas de salvaguardia, en conformidad con las obligaciones que les corresponden en virtud de esos Acuerdos. (OMC, 2003: Párrafo 514).

\section{Conclusiones}

Se indagaron tres casos en materia de salvaguardia comercial prevista en el Acuerdo de Salvaguardias de la $\mathrm{OMC}$, resueltos por el sistema de solución de diferencias de la $\mathrm{OMC}$, que son ilustrativos, porque participaban en unos, países como Argentina, que es miembro de un esquema regional como MERCOSUR; y en otros Estados Unidos que entre otros, tiene un acuerdo de libre comercio con Canadá y México, y todos son miembros de la OMC.

En ellos, se pudo observar que la posibilidad de excluir la aplicación de medidas de salvaguardia multilateral a las importaciones de países pertenecientes a una acuerdo de libre comercio, estaría justificada sólo en dos supuestos : a) cuando las importaciones que están excluidas de la aplicación de la medida de salvaguardia no fueron tomadas en consideración en 
la investigación para la determinación del daño grave, o, b) cuando, las importaciones excluidas de la aplicación de la medida de salvaguardia fueron examinadas en la determinación del daño grave, pero las autoridades competentes han establecido explícitamente, con una explicación razonada y adecuada, que las importaciones procedentes de fuentes ajenas a la zona de libre comercio satisfacían, por sí solas, las condiciones para la aplicación de una medida de salvaguardia. Sin embargo, como puede advertirse el Órgano de Apelación desestimó las argumentaciones de Argentina, en uno, y de EEUU, por haber considerado que no se produjo una explicación razonada y fundamentada sobre el motivo de la exclusión de la aplicación de las medidas de salvaguardia a determinadas importaciones originarias de zona de libre comercio.

Cabe observar que en los casos examinados el Órgano de Apelación no se pronunció directamente sobre si la pertenencia o no a una zona de libre comercio permitiría o no la posibilidad de excluir la aplicación de una medida de salvaguardia multilateral. Al respecto sostuvo que no prejuzga si el párrafo 2 del artículo 2 del Acuerdo sobre Salvaguardias permite a un Miembro excluir del ámbito de aplicación de una medida de salvaguardia las importaciones procedentes de Estados miembros de una zona de libre comercio.

Sin embargo, de la revisión de los argumentos esbozados en el ámbito multilateral en las causas señaladas, se puede derivar, que cuando un país pretende aplicar una medida de salvaguardia multilateral, podría excluir tanto del ámbito de investigación para la determinación del daño, como del ámbito de aplicación a las importaciones de determinados países, siempre y cuando, justifique razonadamente dicha exclusión, en los términos desarrollados por el Órgano de Apelación. Pero el hecho de que se reconozca la posibilidad de excluir ciertas importaciones, lleva implícita una discriminación, a los efectos de aplicar una medida de salvaguardia multilateral. Como se ha observado de los casos examinados en ese organismo multilateral, la posibilidad de exceptuarse de la aplicación de una norma multilateral no ha sido justificada por la pertenencia o no a una zona de libre comercio.

En principio, la práctica esperada de los Estados participantes debería ser la eliminación de restricciones al comercio ya sean unilaterales, o justificadas, tanto en el comercio regional como en el multilateral. No obstante, la posibilidad de aplicar instrumentos jurídicos en materia de salvaguardia comercial es una opción que contemplan los países, que jurídicamente está permitido en la medida que se encuadren en los supuestos normativos previstos en las normas y sea debidamente justificado por el país que la pretenda aplicar. La aplicación de este tipo de medidas ha dado lugar a controversias sobre su aplicación como ha podido notarse en este trabajo. Y este tipo de diferencias podrían continuar produciéndose. En ese sentido, se puede observar que, si bien, las normas en un principio pretenden regular situaciones y ordenar la conducta de los actores y por ende, facilitar la previsibilidad en escenario internacional, la complejidad y entrelazamiento de los actores participantes en el comercio internacional, desafían las motivaciones y presupuestos normativos.

\section{Bibliografía}

Czar de Zalduendo, S. (2007). El Sistema jurídico internacional y sus tensiones: fragmentación y vocación universal. Buenos Aires: Universidad de Bolonia, Puente Europa, año 5, no 2. 
Hasenclever et al. (1999). Las Teorías de los Regímenes internacionales: situación actual y propuesta para una síntesis. Ciudad de México: El Colegio de México, Centro de Estudios Internacionales. octubre-diciembre.

Hummer W. \& Prager D. (1998). GATT, ALADI y NAFTA. Buenos Aires: Ciudad Argentina, Fundación Centro de Estudios Políticos y Administrativos.

Hurrell, A. (1992). Teoría de Regímenes Internacionales: Una perspectiva Europea. Ciudad de México: El Colegio de México, Centro de Estudios Internacionales. octubre-diciembre.

Iglesias E. (2004). Solución de Controversias Comerciales Intergubernamentales: Enfoques Multilaterales y Regionales. Buenos Aires: BID-INTAL.

Keohane R. y Nye J. (1988). Poder e Interdependencia. Buenos Aires: Grupo Editor Latinoamericano, Colección Estudios Internacionales.

Krasner, S. (1976). "State Power and the Structure of International Trade" World Politic.Vol.28, n 3. (April), pp. 317-347. Http://links.jstor.org/sici?sici=00438871\%28197604\%2928\%3A3\%3C317\%3ASPATSO\%3E2.0.CO\%3B2-B. [Consulta: 2018, marzo 6].

Lacarte J. \& Granados J. (2004). Solución de controversias comerciales intergubernamentales, Enfoques Multilaterales y regionales. Buenos Aires: BID, INTAL.

Organización Mundial del Comercio (2017). Entendimiento sobre Solución de diferencias (ESD). http:// www.wto.org. (Consulta: 2017, junio 2].

Organización Mundial del Comercio (2017). Entender la OMC. Solución de diferencias. http:// www.wto.org . [Consulta: 2017, junio 3].

Organización Mundial del Comercio (2017). Lista cronológica de las diferencias http://www.wto.org/spanish/tratop_s/dispu_s/dispu_status_s.htm.[Consulta: 2017, junio 3].

Organización Mundial del Comercio. Acuerdo sobre Salvaguardias. Textos jurídicos. https://docs.wto.org/ .[Consulta: 2017, junio 2].

Organización Mundial del Comercio (2017). Informes del Órgano de Apelación. https://www.wto.org/spanish/tratop_s/dispu_s/ab_reports_s.htm. [Consulta: 2017, junio 4].

Pérez Gabilondo, J. (2004). Manual sobre solución de controversias en la Organización Mundial del Comercio. Buenos Aires: EDUNTREF de la Universidad de Tres de febrero.

Rojas Aravena, F. y Altmann, J. (2006). "Multilateralismo e Integración en América Latina y el Caribe". Seminario Internacional: Paradojas de la Integración en América Latina. Santiago de Chile: CEPAL-FLACSO-Fundación Carolina. 